\title{
AVALIAÇÃO DE CULTIVARES DE SORGO SACARINO [Sorghum bicolor (L.) MOENCH] EM DIFERENTES DENSIDADES DE SEMEADURA VISANDO A CARACTERÍSTICAS IMPORTANTES NA PRODUÇÃO DE ETANOL
}

\author{
ISRAEL ALEXANDRE PEREIRA FILHO ${ }^{1}$, RAFAEL AUGUSTO DA COSTA PARRELLA ${ }^{1}$, JOSÉ ALOÍSIO \\ ALVES MOREIRA ${ }^{1}$, ANDRÉ MAY ${ }^{1}$, VANDER FILLIPE DE SOUZA² e JOSÉ CARLOS CRUZ ${ }^{1}$ \\ ${ }^{1}$ Embrapa Milho e Sorgo, Sete Lagoas, MG, Brasil, israel.pereira@embrapa.br, rafael.parrela@embrapa.br, \\ jose.aloisio@embrapa.br,andre.may@embrapa.br,josecarlos.cruz@embrapa.br \\ ${ }^{2}$ Universidade Federal de São João del-Rei, São João del-Rei, MG, Brasil,vander_agro@hotmail.com
}

$$
\overline{\text { Revista Brasileira de Milho e Sorgo, v.12, n.2, p. 118-127, } 2013}
$$

\begin{abstract}
RESUMO - Ao lado da cana-de-açúcar, planta tradicionalmente empregada na produção de etanol, o sorgo sacarino apresenta-se como uma excelente opção sob os pontos de vista agronômico e industrial, por oferecer as vantagens de ser uma planta tolerante a déficit hídrico de ciclo curto, ser totalmente mecanizada, possuir colmos suculentos com açúcares totalmente fermentáveis e com produção de massa verde variando de 40 a $60 \mathrm{t} \mathrm{ha}^{-1}$. O trabalho foi conduzido na área experimental da Embrapa Milho e Sorgo em janeiro de 2011, em solo classificado como Latossolo Vermelho Distroférrico, objetivando verificar o efeito de diferentes cultivares de sorgo sacarino e densidades de semeadura no teor de sólidos solúveis totais. Foram utilizados quatro cultivares de sorgo sacarino (variedades) BR 501; 505 ; 506 e 507 e um híbrido simples forrageiro BR 601, o qual serviu de testemunha, semeados nas densidades de semeaduras de 75.000, 100.000, 125.000, 150.000 e 175.000 plantas ha $^{-1}$. Foram avaliados os parâmetros cultivares, densidades de semeadura e as características altura da planta, produção de massa verde, volume de caldo e teor de açúcares redutores totais. Os resultados mostraram que o peso de massa verde aumentou linearmente com a elevação do número de plantas por área e que a cultivar BR 506 foi a que apresentou maior rendimento. O volume de caldo aumentou com a elevação da densidade de semeadura, sendo maior nas cultivares BR 506 e BR 505, e o ${ }^{\circ}$ Brix, indicador do teor de açúcar na planta de sorgo sacarino, não diferiu entre as cultivares avaliadas no trabalho.
\end{abstract}

Palavras-chave: Sorghum bicolor; arranjo de plantas; massa verde; sólidos solúveis totais.

\section{EVALUATION OF SWEET SORGHUM [Sorghum bicolor (L.) MOENCH] CULTIVARS IN DIFFERENTS SOWING DENSITIES REGARDING IMPORTANT CHARACTERISTICS IN ETHANOL PRODUCTION}

\begin{abstract}
Together with sugar cane, a traditional plant used to produce ethanol, sweet sorghum is an excellent option under the agronomic and industrial points of view, since this plant is tolerant to water deficit, presents short cycle and can be totally mechanized. In addition, this plant has succulent stems with totally fermentable sugars and the green matter production ranges from 40 to $60 \mathrm{t} \mathrm{ha}^{-1}$. The work was conducted at the Embrapa Maize and Sorghum in January 2011 in a soil classified as Distroferric Red Latosol, aiming to verify the effect of different sweet sorghum cultivars and sowing densities on the total soluble solids. Four cultivars (varieties) of sweet sorghum were used, BR 501; 505; 506; 507 and a simple forage hybrid BR 601 as control, seeded at sowing densities of 75,000;100,000; 125,000; 150,000 and 175,000 plants per hectare. The parameters evaluated were cultivars and seeding densities Plant height, green mass production, broth volume and total reducing sugar were the traits evaluated. The results showed that the weight of green mass increased linearly with the increase of the number of plants per area and the BR 506 cultivar presented the highest yield. The volume of broth increased with the elevation of seeding densities, being higher in the BR 506 and BR 505 cultivars The ${ }^{\circ}$ Brix, an indicator of sugar content in sweet sorghum plant, did not differ among the cultivars evaluated.
\end{abstract}

Key words: Sorghum bicolor; plant arrangement; green mass; total solids soluble.

Versão impressa ISSN 1676-689X / Versão on line ISSN 1980-6477 http://www.abms.org.br 
O sorgo é uma planta de metabolismo $\mathrm{C}_{4}$, de dias curtos e com altas taxas fotossintéticas. E é considerado uma "smart crop" em função de produzir combustível através da biomassa e açúcares fermentáveis que, industrializados, transformam-se em etanol e/ou em alimento. Em se tratando de uma cultura de ciclo vegetativo curto, de 90 a 130 dias, apresenta-se ideal para o complemento na produção de etanol durante o período de entressafra da cana-de-açúcar, ou quando a cana-de-açúcar ainda se encontra em estado de desenvolvimento vegetativo e possui pouca concentração de açúcares, permitindo ampliar o período de uso das usinas de etanol em três meses. Ele também pode ser adequado em um sistema integrado de exploração da propriedade rural, objetivando a autossuficiência de energia, aliada a outras atividades voltadas para a produção agropecuária (Souza et al. 2005).

O sorgo sacarino como matéria prima para produção de etanol oferece as vantagens de ser uma planta tolerante a déficit hídrico, ciclo curto, mecanizada, possui colmos suculentos com açúcares totalmente fermentáveis e com produção de massa verde variando de 40 a $60 \mathrm{t} \mathrm{ha}^{-1}$. O bagaço gerado pela extração do caldo serve também como fonte de energia para a indústria e geração de eletricidade, bem como permite a produção de etanol de segunda geração, e também como fonte de alimentação animal. (Oliveira \& Ramalho, 2006; Lourenço et al., 2010).

São poucos os trabalhos relacionados com o manejo cultural do sorgo sacarino. Entretanto, ressaltam-se alguns trabalhos, como de Cowley \& Smith (1972), no qual verificou-se que os rendimentos obtidos na cultura do sorgo sacarino são diretamente influenciados pelo comprimento dos dias e pela radiação solar global. Os melhores rendimentos em açúcares por área de cultivo estão estreitamente relacionados com dias mais longos e radiação solar máxima.

Avaliando cultivares de sorgo sacarino em rede nacional de ensaio em Santa Maria, RS, Marchezan \& Silva (1984) verificaram que uma das cultivares mais promissoras foi a BR 505, com um rendimento de massa verde de $46 \mathrm{t} \mathrm{ha}^{-1}$ e teor de açúcares redutores totais de $16 \%$ no caldo extraído. Resultado semelhante em relação à cultivar BR 505, boa produtora de massa verde e alto teor de açúcares redutores, também foi observado por Teixeira et al (1999).

Em trabalho de revisão, Almodares \& Hadi (2009) relacionaram 36 materiais de sorgo sacarino entre variedades, híbridos e linhagens e encontraram variações no rendimento de massa verde de 27,9 a 128,9 $\mathrm{t} \mathrm{ha}^{-1}$, com ${ }^{\circ}$ Brix variando de 14,3 a 23,1, sacarose de 6,0 a $16,0 \%$ e pureza de 35,9 a $76,0 \%$. Albuquerque et al. (2010) estudaram arranjos de plantas, duas cultivares e quatro densidades de semeaduras associadas a quatro espaçamentos entre fileiras, e verificaram que a redução do espaçamento provoca maior produtividade de matéria verde e reduz a altura das plantas em função do local de cultivo. A cultivar BR 507 apresentou melhor desempenho nos três locais avaliados.

O objetivo deste trabalho foi avaliar cultivares de sorgo sacarino em diferentes densidades de semeadura, visando a verificar características importantes na produção de etanol.

\section{Material e Métodos}

O trabalho foi conduzido na área experimental da Embrapa Milho e Sorgo em janeiro de 2011, em solo classificado como Latossolo Vermelho Distroférrico, objetivando verificar o efeito de diferentes cultivares de sorgo sacarino e densidades de semeadura 
no teor de açúcares. Foram utilizados quatro cultivares de sorgo sacarino (variedades) BR 501; 505; 506 e 507 e um híbrido simples forrageiro BR 601 (testemunha), semeados nas densidades de 75, 100, 125, 150 e 175 (x1.000) plantas ha ${ }^{-1}$. O desbaste foi realizado deixando em cada tratamento o número de plantas para se ter no final as densidades pretendidas. Utilizou-se o delineamento experimental de blocos ao acaso em esquema de fatorial $5 \times 5$ e três repetições. Cada parcela foi constituída por quatro linhas de $5 \mathrm{~m}$ de comprimento, espaçadas em $0,70 \mathrm{~m}$, e sendo consideradas como área útil as duas linhas centrais, desprezando-se 0,50 m de cada extremidade. A adubação de plantio foi de $300 \mathrm{~kg} \mathrm{ha}^{-1}$ da fórmula 8-28-16 $+\mathrm{Zn}$ e, em cobertura, $200 \mathrm{~kg} \mathrm{ha}^{-1}$ de nitrogênio na forma de ureia, quando as plantas estavam com $40 \mathrm{~cm}$ de altura. A colheita e as tomadas de dados foram realizadas quando os grãos estavam na maturidade fisiológica, ponto no qual se tem a maior concentração de açúcar no colmo. O conteúdo de caldo do colmo foi extraído de uma amostra de $500 \mathrm{~g}$ de material fresco (colmo + folhas) em uma prensa do tipo Hidraseme PHS-250 (245 $\mathrm{kg} \mathrm{cm}^{-1} \mathrm{~min}^{-1}$ ). Os dados obtidos submetidos à análise de variância e foram aplicados testes de comparações múltiplas através do programa SISVAR. Foram avaliados os parâmetros cultivares e densidades de semeadura e as características médias altura da planta, produção de massa verde, volume de caldo e teor de sólidos solúveis totais ( ${ }^{\circ}$ Brix). Para a extração do caldo da massa fresca do colmo, foi retirada uma amostra composta por 10 plantas da área útil de cada parcela, por ocasião da colheita, após as mensurações das características citadas anteriormente.

\section{Resultados e Discussão}

A análise de variância (quadrados médios) das características estudadas está apresentada na Tabela 1, em que observou-se significância ao nível de $1 \%$ de probabilidade para altura da planta, peso de massa

TABELA 1. Quadrados médios, médias e coeficientes de variação (CV) das análises de variância, para as características Altura da Planta (AP), Peso de Massa verde (PMV), Volume de Caldo (VC) e Grau Brix ( ${ }^{\circ}$ Brix). Embrapa Milho e Sorgo. Sete Lagoas, MG. 2011.

\begin{tabular}{lccccc}
\hline Fontes de Variação & GL & AP $(\mathrm{cm})$ & PMV $\left(\mathrm{t} \mathrm{ha}^{-1}\right)$ & VC $\left(1 \mathrm{ha}^{-1}\right)$ & ${ }^{\circ}$ Brix \\
\hline Cultivares (C) & 4 & $0,447^{* *}$ & $1475,327^{* *}$ & $152235411,507^{* *}$ & 0,376 \\
Dens. Semeadura (D) & 4 & $0,040^{* *}$ & $3535,255^{* *}$ & $276856794,205^{* *}$ & 0,416 \\
C x D & 16 & $0,124^{* *}$ & 105,654 & 26836770,205 & 1,105 \\
Tratamento & 24 & 0,162 & 905,533 & 89406547,884 & 1,714 \\
Blocos & 2 & 0,029 & 520,444 & 76478721,832 & $7,740^{*}$ \\
Resíduo & 48 & 0,006 & 114,078 & 16551320,429 & 1,972 \\
\hline Média & & 2,75 & 73,992 & 25,310 & 15,62 \\
CV $(\%)$ & 2,88 & 14,43 & 19,09 & 8,96 \\
\hline
\end{tabular}

*, ** significativos, aos níveis de $5 \%$ e $1 \%$, pelo teste de $\mathrm{F}$, respectivamente. 
verde e volume de caldo para as variáveis cultivares e densidade de semeadura, com exceção da altura da planta, que apresentou também significância para a interação cultivares x densidade de semeadura.

A altura da planta foi maior nas cultivares BR 505 e 506, as quais tiveram comportamento idêntico, com patamar de altura de 2,92 e 2,91 m, respectivamente, evidenciando não haver diferença significativa entre as mesmas. (Figura 1).

A interação cultivares $\mathrm{x}$ densidades foi altamente significativa, mostrando que a característica altura de planta da cultivar BR 501 foi a que mais respondeu à elevação da densidade de plantas por área. Já a cultivar BR 506, maior produtora de caldo, teve comportamento contrário, ou seja, à medida que elevou o número de plantas por área, teve sua estatura reduzida, o que, geralmente, induz as plantas dessa cultivar a um menor acamamento ou quebramento (Figura 2).

A característica acamamento de planta interfere no processo de colheita, tanto dificultando as operações como aumentando as perdas de biomassa e de rendimento de caldo e açúcares. A estatura muito elevada de cultivar pode estar sujeita ao acamamento devido a vários fatores, como a ação de ventos fortes. Neste experimento, o número de plantas acamadas foi muito pequeno e desprezível.

O peso de massa verde reflete positivamente na produção de caldo. Entretanto, o conteúdo de açúcares no caldo e, por consequência, a conversão

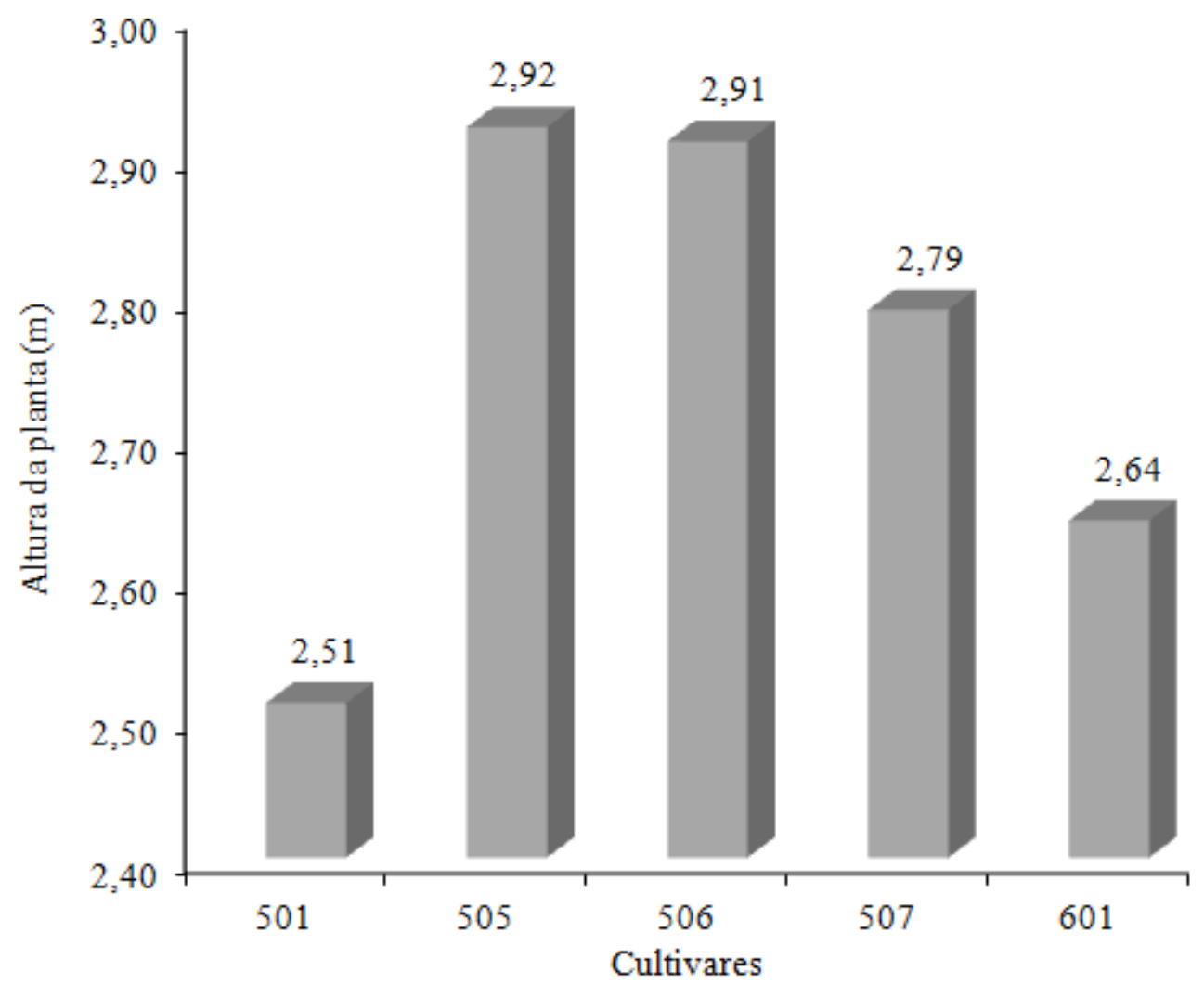

FIGURA 1. Altura média da planta, obtida de diferentes cultivares de sorgo sacarino e densidade de semeadura. Sete Lagoas, MG. 2011. 


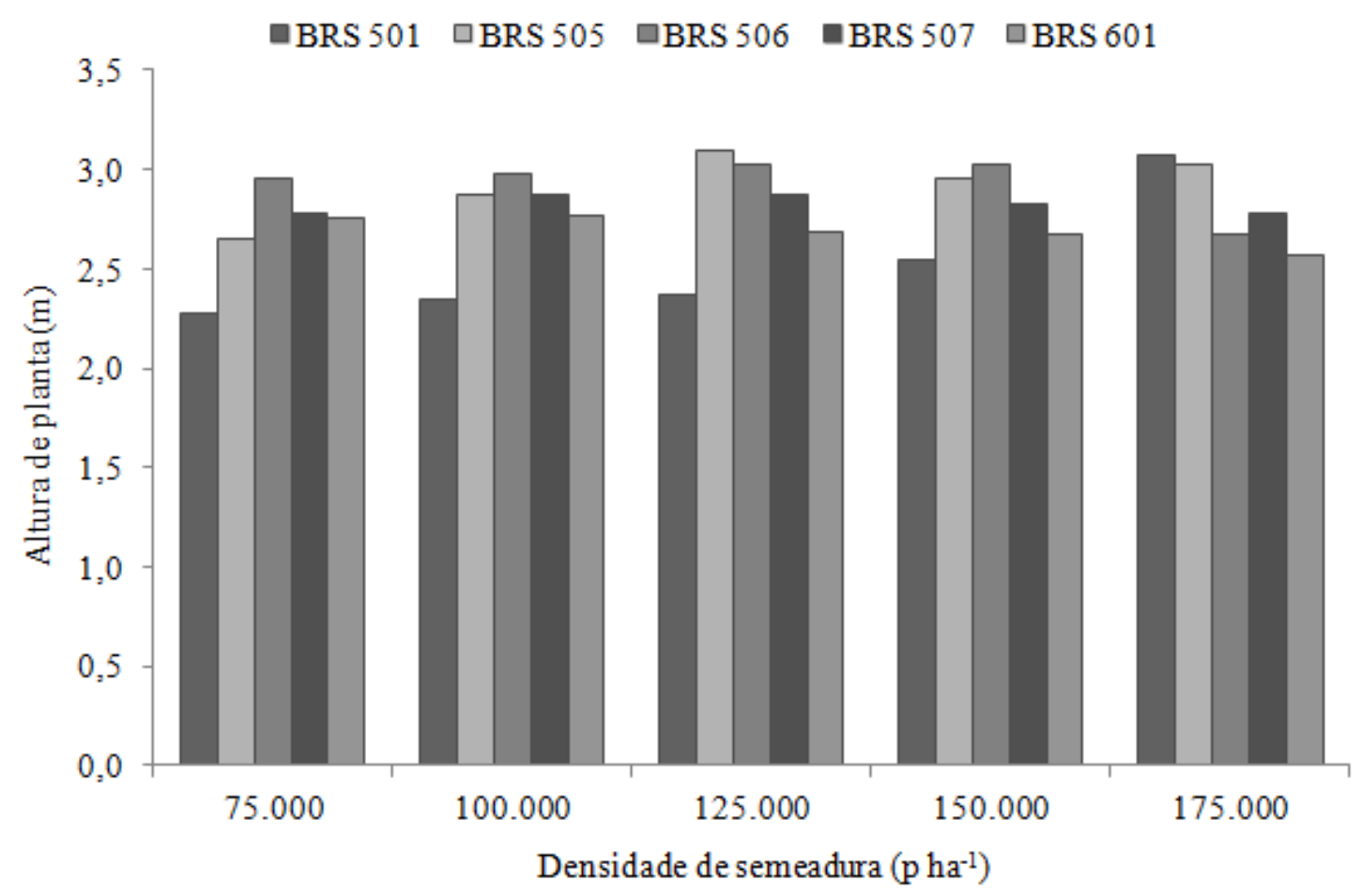

FIGURA 2. Representação gráfica da interação cultivares x densidades de semeadura. Sete Lagoas, MG. 2011.

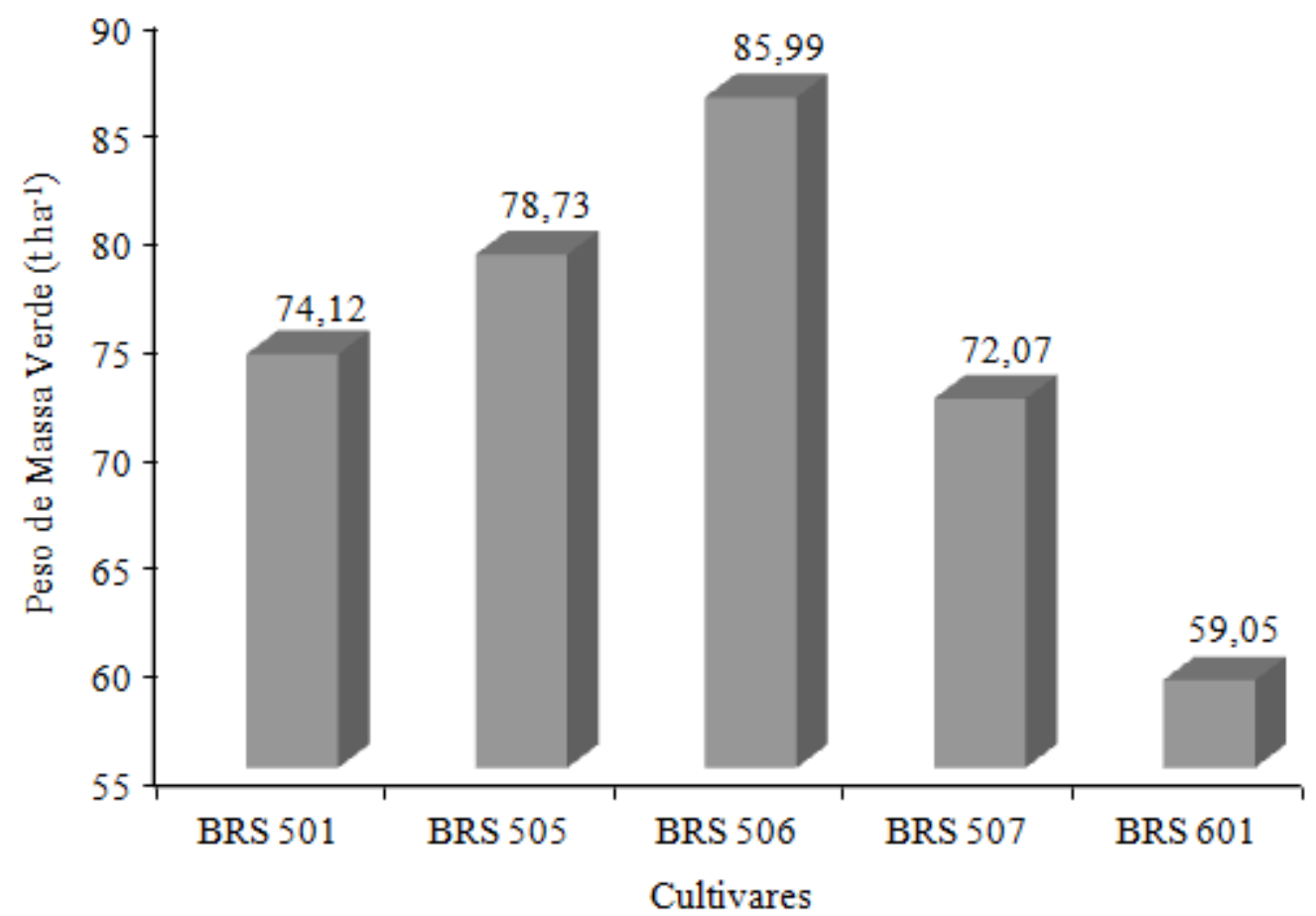

FIGURA 3. Peso médio de massa verde, obtido de cultivares de sorgo sacarino em diferentes densidades de semeadura. Sete Lagoas, MG. 2011. 


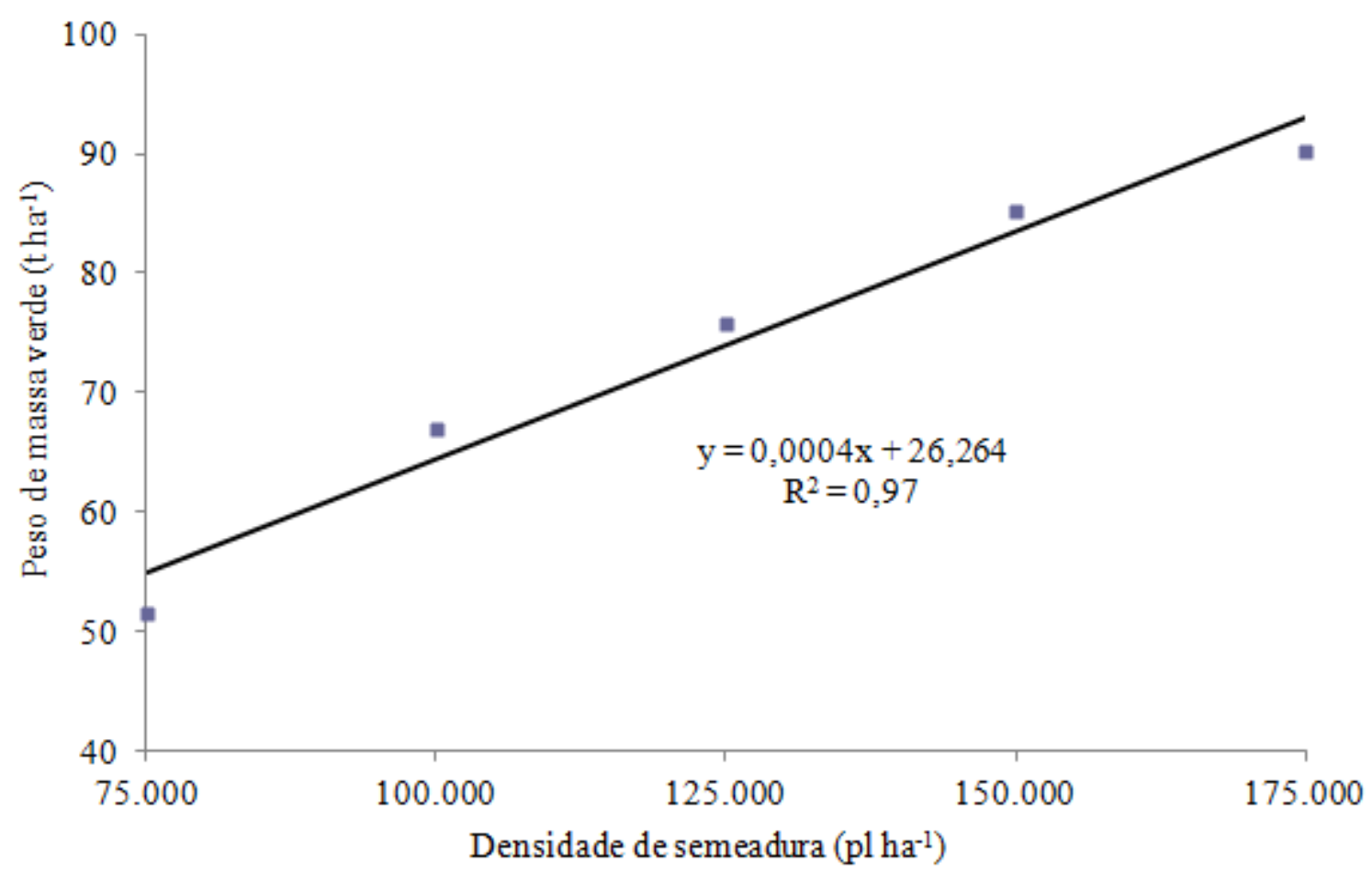

FIGURA 4. Produção média de massa verde $\left(\mathrm{t} \mathrm{ha}^{-1}\right)$ obtida de cultivares de sorgo sacarino em diferentes densidades de semeadura. Sete Lagoas, MG. 2011.

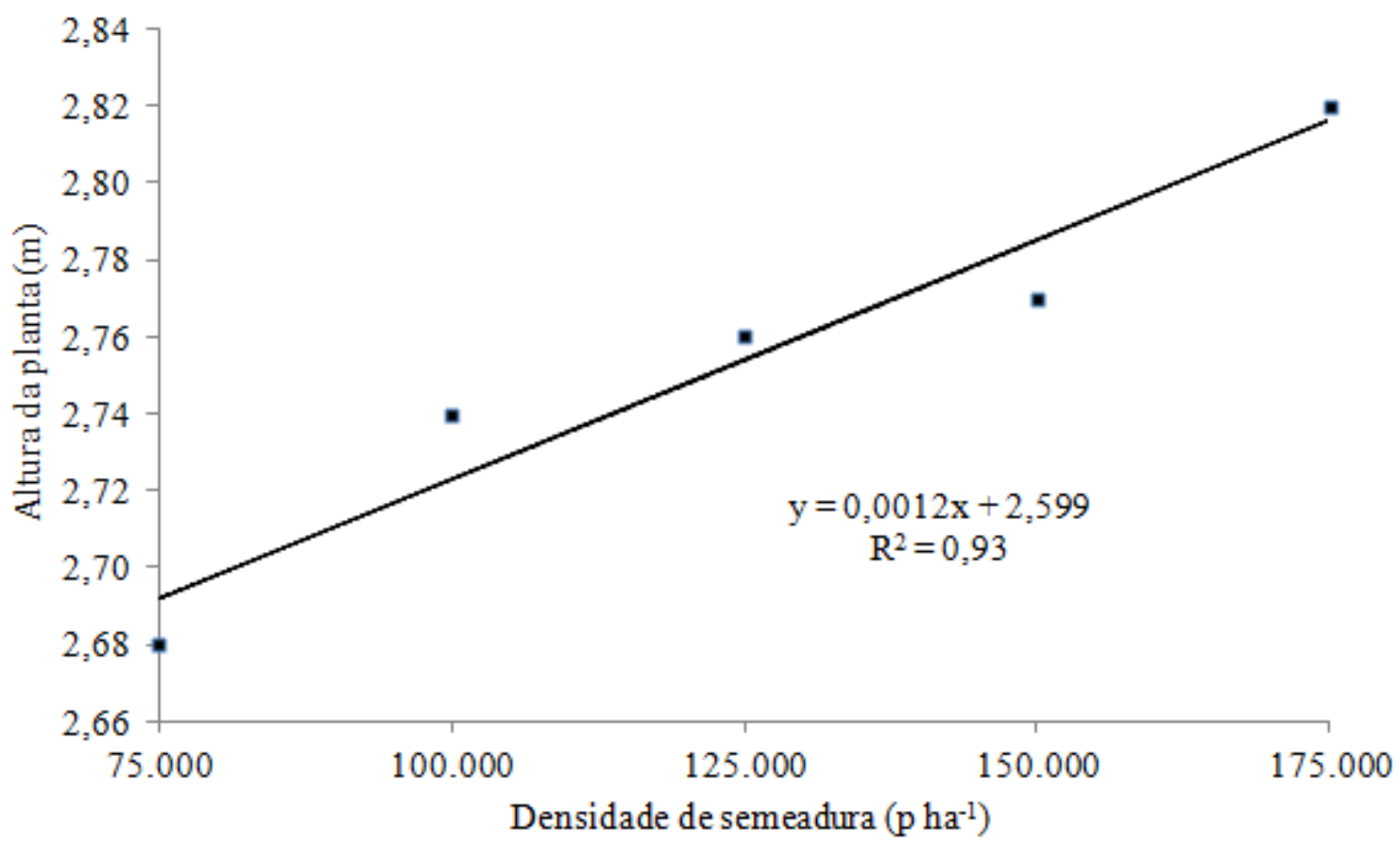

FIGURA 5. Altura média da planta $(\mathrm{cm})$ obtida de cultivares de sorgo sacarino em diferentes densidades de semeadura. Sete Lagoas, MG. 2011. 
em etanol, é dependente da cultivar, fatores ambientais e época de colheita e eficiência de processos de transporte e de conversão industrial. O peso de massa verde mostrou-se altamente significativo para cultivares e densidade de semeadura (Tabela 1). Em relação a cultivares, a variedade BR 506 produziu cerca de 86,0 $\mathrm{t} \mathrm{ha}^{-1}$, seguida pela BR 505, com 78,7 t $\mathrm{ha}^{-1}$, o que representa uma pequena diferença de 7,3 $\mathrm{t}$ ha $^{-1}$, ou 8,5\%. Estes resultados, em relação à cultivar BR 505, assemelham-se com aqueles obtidos por Marchezan \& Silva (1984), com destaque para o rendimento do peso massa verde da cultivar obtido neste trabalho, que foi maior que aquele apresentado pelos autores. Já em relação à cultivar BR 507, os resultados obtidos por Albuquerque et al. (2010) mostraram que a mesma apresentou melhor desempenho em três localidades do Norte de Minas, contrariando os resultados obtidos nesta pesquisa, em que a mesma cultivar apresentou-se como a menos produtiva entre as estudadas. As variedades BR 501 e BR 507 tiveram entre si também uma pequena diferença, evidenciada na Figura 3. Entretanto, o sorgo BR 601, híbrido simples, teve o pior desempenho, por não apresentar as mesmas características genéticas das cultivares BR 506, 505, 501 e 507, desenvolvidas para suportar maior pressão de plantas por área e maior teor de açúcar. A diferença da maior produção de massa verde 86,0 t ha ${ }^{-1}$ (BR 506) para a menor, $54,1 \mathrm{t} \mathrm{ha}^{-1}$, produzida pelo híbrido BR 601 , representa uma diferença de $37,1 \%$. Os rendimentos de massa verde obtidos neste trabalho estão dentro da amplitude de rendimento de massa verde (27,9 a $124 \mathrm{t} \mathrm{ha}^{-1}$ ) encontrada por Almodares \& Hadi (2009) dentre 36 materiais de sorgo sacarino (variedades, híbridos e linhagens).

A densidade de semeadura influenciou significativamente $(\mathrm{p} \leq 0,01)$ o peso médio de massa verde e

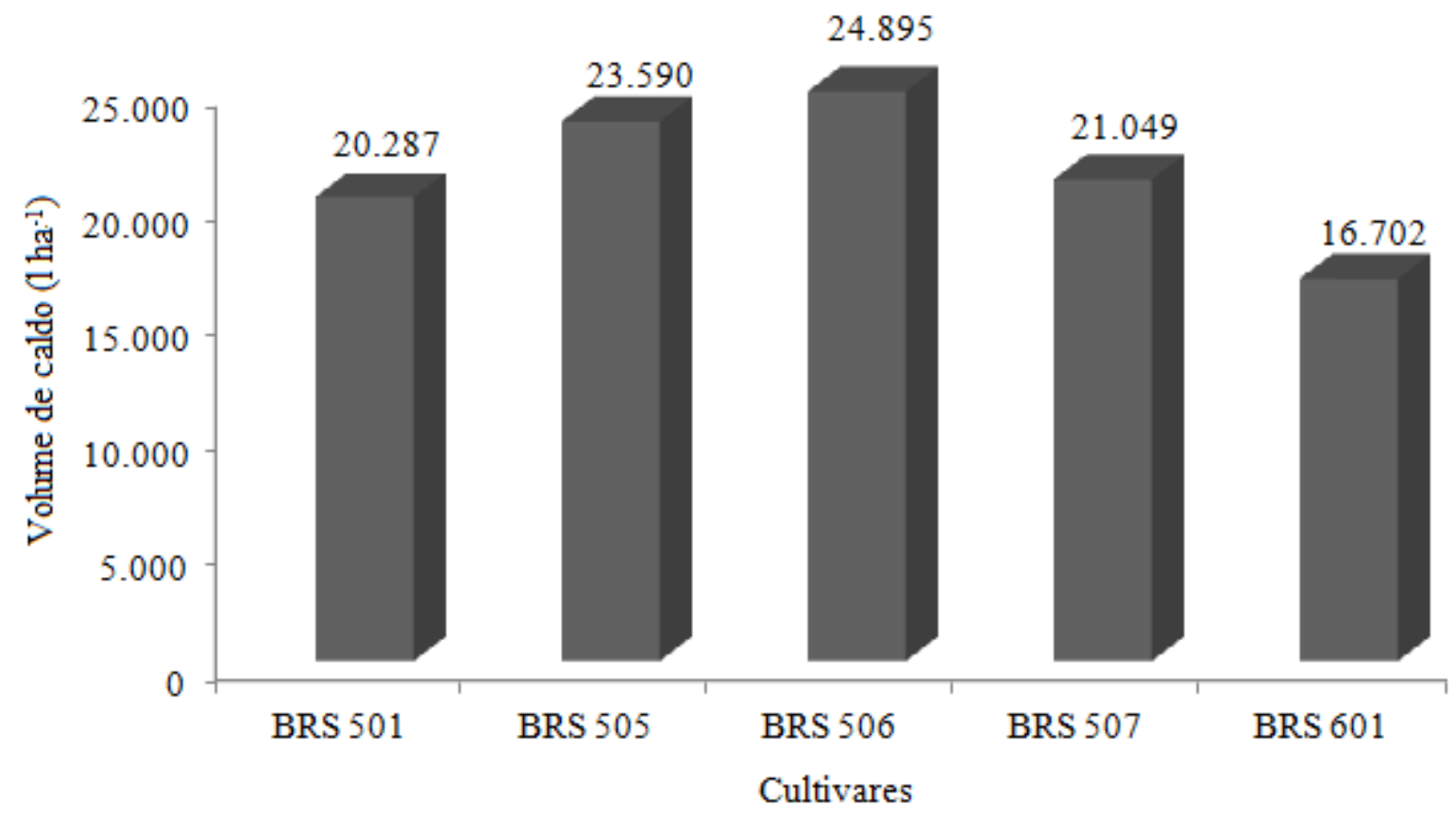

FIGURA 6. Volume médio de caldo $\left(1 \mathrm{ha}^{-1}\right)$ obtido de cultivares de sorgo sacarino em diferentes densidades de semeadura. Sete Lagoas, MG. 2011. 
a altura média da planta, mostrando crescimento linear das características à medida que se elevou o número de plantas por área, como evidenciam as Figuras 4 e 5.

A relação entre o peso médio de massa verde e as densidades de semeadura utilizadas permitiu um bom ajuste na equação de regressão, evidenciada pelo valor de $\mathrm{R}^{2}=0,97$. $\mathrm{O}$ aumento linear do rendimento de massa verde obtido no trabalho, em decorrência da elevação da densidade de semeadura, também foi observado por Albuquerque et al. (2010), que, em estudos de arranjos de plantas envolvendo cultivares, densidades de semeaduras e espaçamentos entre fileiras, verificaram também que o aumento da densidade de semeadura proporcionou maior produtividade de massa verde. Entretanto, em relação à altura da planta, o ajuste da equação foi menos preciso, como mostra o valor de $\mathrm{R}^{2}=0,93$ na equação de regressão da Figura 5.

O volume médio de caldo foi influenciado pelas cultivares $(\mathrm{p} \leq 0,01)$, mostrando maior valor da característica para a cultivar BR 506, com 24.8951 $\mathrm{ha}^{-1}$, seguida da BR 505, que produziu $23.2861 \mathrm{ha}^{-1}$. Entretanto, no que se refere às demais cultivares (BR 505, 507, 501 e 601), as diferenças em relação à cultivar mais produtiva foram, respectivamente, 1.609 1 ha $^{-1}, 3.8461$ ha $^{-1}, 4.6091$ ha $^{-1}$ e 8.1941 ha $^{-1}$.

A maior diferença observada do no volume de caldo entre as cultivares BR 506 e BR 601 (8.194 1 ha $^{-1}$ ) deve-se ao fato de que a BR 601 não apresenta as mesmas características genéticas da cultivar BR 506, que foi desenvolvida para ser uma planta capaz de suportar maior pressão de plantas por área.

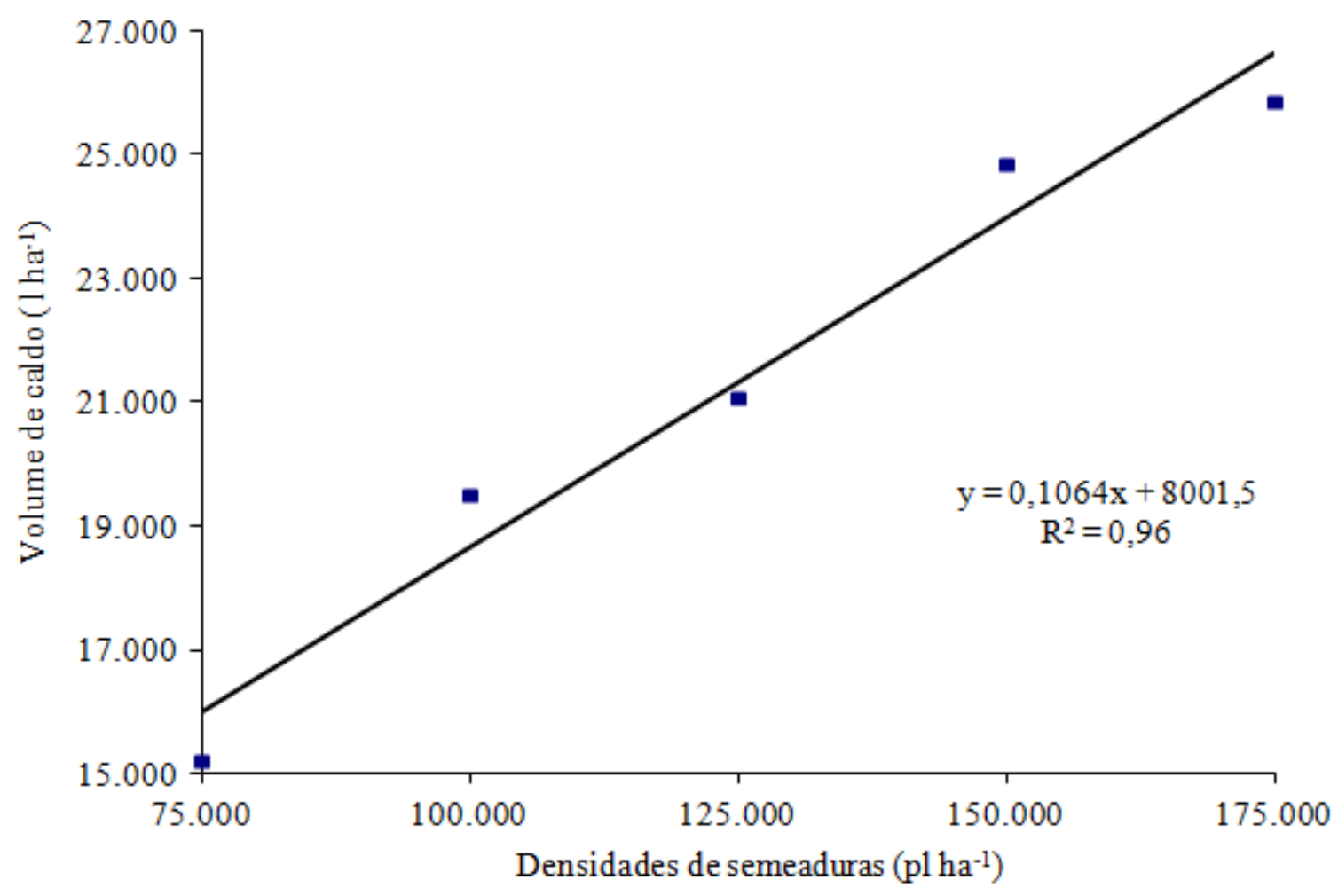

FIGURA 7. Produção média do volume de caldo $\left(1 \mathrm{ha}^{-1}\right)$ obtida de cultivares de sorgo sacarino em diferentes densidades de semeadura. Sete Lagoas, MG. 2011. 


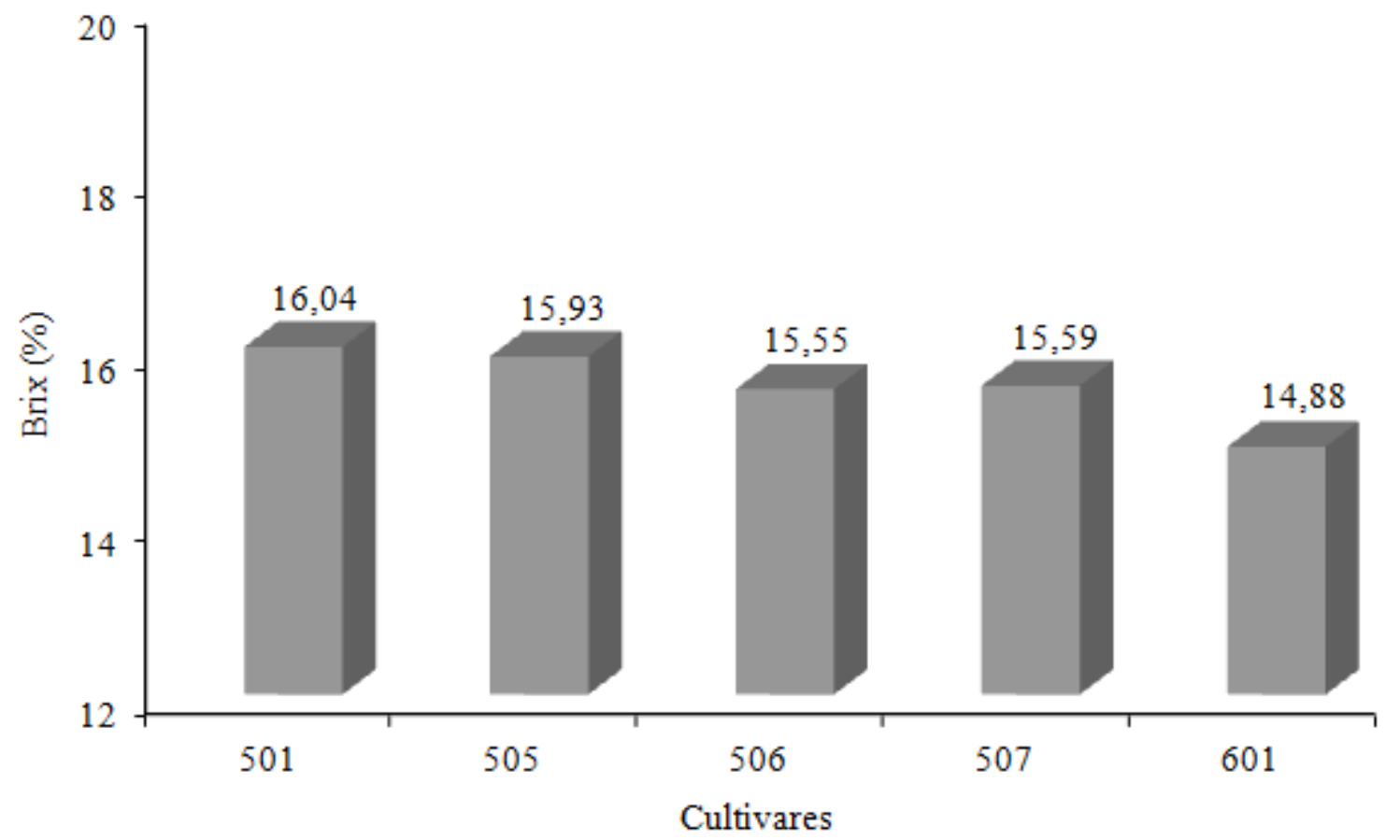

FIGURA 8. Grau Brix médio obtido de cultivares de sorgo sacarino em diferentes densidades de semeadura. Sete Lagoas, MG. 2011.

A elevação do número de plantas por área, também influenciou significativamente o volume de caldo (Tabela 1). A equação de regressão $\left(\mathrm{R}^{2}=0,96\right)$ mostra um bom ajuste dos valores de produção de caldo devido ao aumento da densidade de semeadura (Figura 7).

Não foi verificada diferença significativa no Brix entre as cultivares ou densidades de semeadura estudadas como mostra a análise da variância (Tabela 1). Apesar de não diferir significativamente entre as cultivares estudadas, a cultivar BR 601 apresentou o menor valor $\left(14,88^{\circ}\right.$ Brix) (Figura 8).

As cultivares BR 501 e 505 apresentaram os maiores teores de açúcar, expressos em 16,04 e $15,93^{\circ}$ Brix, respectivamente; e, a BR 601, apresentou o menor teor $\left(14,88{ }^{\circ}\right.$ Brix $)$. Almodares \& Hadi (2009) trabalhando com materiais de sorgo sacarino (variedades, híbridos e linhagens), encontraram valores que variaram de 14,32 a $23,85^{\circ}$ Brix.

O desenvolvimento de plantas em maiores densidades de semeadura resultou em maior produção de biomassa, e proporcionou um maior volume de caldo na BR 506. Cabe ressaltar, que para sorgo sacarino, o maior volume de caldo nem sempre configura em maior produção de açúcares; e, portanto, em maior rendimento em etanol. Com base nos resultados obtidos, especialmente no que diz respeito à variável densidade de semeadura, sugerem-se novos trabalhos envolvendo arranjos espaciais (espaçamentos e densidades de plantas por área), visando analisar ponto de máxima produtividade física e econômica para a produção de biomassa (verde e seca), altura de planta e acamamento, volume de caldo e teores de açúcares, rendimento de etanol. 


\section{Conclusões}

As cultivares BR 505 e BR 506 apresentaram as maiores alturas de planta, e no geral a média dessa característica aumentou linearmente com a elevação da densidade de semeadura por área.

O peso de massa verde aumentou linearmente em relação a elevação do número de plantas por área, enquanto somente a cultivar BR 506, apresentou a maior produção para a característica.

O volume de caldo aumentou com a elevação da densidade de semeadura, observando se os maiores valores para a característica nas cultivares BR 506 e BR 505.

O Brix não diferenciou entre as cultivares e as densidades de semeadura avaliadas no trabalho.

\section{Referências}

AlBuQUERQUE, C. J. B.; PARRELA, R. A. C.; TARDIN, F. D.; BRANT R. S.; SIMÕES D. A.; FONSECA JR, W. B.; OLIVEIRA R. M.; JESUS, K. M. Potencial Forrageiro de Cultivares de Sorgo Sacarino em Diferentes Arranjos de Plantas e Localidades de Minas Gerais. In: Congresso Nacional de Milho e Sorgo, 28.; SIMPÓSIO BRASILEIRO SOBRE A LAGARTA DO CARTUCHO, 4., 2010, Goiânia. Potencialidades, desafios e sustentabilidade: resumos expandidos... Goiânia: ABMS, 2010. 1 CD-ROM.

ALMODARES, A.; HADI, M. R. Production of bioethanol from sweet sorghum: A review. African Journal of Agricultural Research, Nairobi, v. 4, n. 9, p. 772-780, Sept. 2009. Disponível em: http://www.academicjournals.
org/AJAR. Acesso em: 19 out. 2011.

COWLEY, O. H.; SMITH, B. S. Sweet sorghum as a potential sugar crop in south Texas. In: CONGRESS OF THE INTERNATIONAL SOCIETY OF SUGAR CANE TECHNOLOGY, 14., 1971, New Orleans Proceedings..., New Orleans: [s.n.], 1972. p. 628-633.

LOURENÇO, M. E. V., MASSA, V. M. L., PALMA, P. M. M.; RATO, A. E. M. Potencialidades do sorgo sacarino [Sorghum bicolor (L.) Moench] para a produção sustentável de bioetanol no Alentejo. Revista de Ciências Agrárias, Belém, v. 30, n. 1, p. 103-110, 2010.

MARCHEZAN, E.; SILVA, M. I. Avaliação de cultivares de sorgo sacarino em Santa Maria, RS. Revista do Centro de Ciências Rurais, Santa Maria, v. 14, p. 161-172, 1984.

OLIVEIRA, A. J.; RAMALHO J. (Coord.). Plano Nacional de Agroenergia: 2006 - 2011. 2. ed. rev. Brasília, DF: Embrapa Informação Tecnológica, 2006. 110 p.

SOUZA, C. C.; DANTAS, J. P.; SILVA, S. M.; SOUZA, V. C.; ALMEIDA, F. A.; SILVA, L. E. Produtividade do Sorgo granífero cv. sacarino e qualidade de produtos formulados isoladamente ou combinados ao caldo de cana-de-açúcar. Ciência e Tecnologia de Alimento, Campinas, v. 25, n. 3, p. 512-517, 2005.

TEIXEIRA, C. G.; JARDINE J. G.; NICOLELLA, G.; ZARONI, M. H. Influência da época de corte sobre o teor de açúcares de colmos de sorgo sacarino. Pesquisa Agropecuaria Brasileira, Brasília, DF, v. 34, n. 9, p. 16011606, set. 1999 